\title{
Lipodystrophy-like features after total body irradiation among survivors of childhood acute leukemia
}

\author{
Sandrine Visentin ${ }^{1,2}$, Gérard Michel ${ }^{1,3}$, Claire Oudin ${ }^{1,3}$, Béatrice Cousin ${ }^{4}$, Bénédicte Gaborit' ${ }^{2}$ Inès Abdesselam ${ }^{2}$, \\ Marie Maraninchi ${ }^{2}$, Marion Nowicki ${ }^{2}$, René Valéro ${ }^{2,5}$, Maxime Guye ${ }^{6}$, Monique Bernard ${ }^{6,7}$, Pascal Auquier ${ }^{3}$, \\ Hervé Chambost ${ }^{1}$, Marie-Christine Alessi ${ }^{2}$ and Sophie Béliard ${ }^{2,5}$
}

\author{
1Department of Pediatric Hematology and Oncology, AP-HM, Timone Enfants Hospital, Marseille, France \\ ${ }^{2}$ Aix Marseille University, INSERM, INRA, C2VN, Marseille, France \\ ${ }^{3}$ Research Unit EA 3279 and Department of Public Health, Aix-Marseille University, Marseille, France \\ 4STROMALab, Université de Toulouse, CNRS ERL5311, EFS, INP-ENVT, INSERM U1031, UPS, Toulouse, France \\ ${ }^{5}$ Nutrition, Metabolic Diseases and Endocrinology Department, AP-HM, La Conception Hospital, Marseille, France \\ ${ }^{6}$ AP-HM, Timone, CEMEREM, Marseille, France \\ ${ }^{7}$ Aix-Marseille University, CNRS, CRMBM, Marseille, France
}

Correspondence should be addressed to S Visentin: Sandrine.visentin@ap-hm.fr

\begin{abstract}
Background/objective: The number of long-term survivors of childhood acute leukemia $(A L)$ is substantially growing. These patients are at high risk for metabolic syndrome (MS), especially those who received total body irradiation (TBI). The consequences of children's irradiation on adipose tissue (AT) development in adulthood are currently unknown. The objective of this study is to assess the impact of TBI on AT of childhood AL survivors. Design: We compared the morphological and functional characteristics of AT among survivors of childhood AL who developed MS and received $(n=12)$ or not received $(n=12) \mathrm{TBI}$.

Subjects/methods: Body fat distribution and ectopic fat stores (abdominal visceral and liver fat) were evaluated by DEXA, MRI and ${ }^{1} \mathrm{H}$-spectroscopy. Functional characteristics of subcutaneous AT were investigated by studying gene expression and pre-adipocyte differentiation in culture.

Results: Patients who have received TBI exhibited a lower BMI (minus $5 \mathrm{~kg} / \mathrm{m}^{2}$ ) and a lower waist circumference (minus $14 \mathrm{~cm}$ ), especially irradiated women. Despite the lower quantity of intra-abdominal AT, irradiated patient displayed a nearly twofold greater content of liver fat when compared to non-irradiated patient (17 vs $9 \%, P=0.008)$. These lipodystrophic-like features are supplemented by molecular abnormalities in subcutaneous AT of irradiated patients: decrease of gene expression of SREBP1 (minus 39\%, $P=0.01$ ) and CIDEA (minus 36\%, $P=0.004$ ) and a clear alteration of pre-adipocyte differentiation.

Conclusions: These results strongly support the direct effect of irradiation on AT, especially in women, leading to specific nonalcoholic fatty liver disease, despite lower BMI. A longterm appropriate follow-up is necessary for these patients.
\end{abstract}
Key Words
- adipocytes
- irradiation
- childhood AL
- metabolic syndrome
- ectopic fat
- hepatic steatosis

https://ec.bioscientifica.com https://doi.org/10.1530/EC-18-0497 (c) 2019 The authors
Published by Bioscientifica Ltd

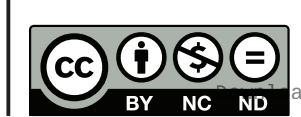

This work is licensed under a Creative Commons Attribution-NonCommercial-NoDerivatives 4.0 elnternationad bicense.ifica.com at 04/26/2023 10:38:39AM
Endocrine Connections (2019) 8, 349-359 


\section{Introduction}

Advances in the treatment strategies and supportive care for childhood acute leukemia (AL) have resulted in marked improvements in survival, which now exceeds $80 \%$ for lymphoblastic and $60 \%$ for myeloid AL (1). However, long-term survivors of childhood AL are at increased risk of later in life complications (2, 3); cardiovascular disease (CVD) is a leading cause of mortality for these patients (2). In a cohort of 10,397 survivors of childhood cancer, the relative risk of having coronary artery disease was 10.4 times higher than for their siblings (2). Metabolic syndrome (MS), a major risk factor for premature CVD and type-2 diabetes mellitus (4), is a common complication in this population $(5,6)$. We have already shown the high prevalence of MS in young adults surviving AL in the LEA cohort ('Leucémie de l'Enfant et de l'Adolescent'): i.e., $9.2 \%$ at a mean age of 21 years (6).

Various factors contribute to metabolic abnormalities after AL treatment: growth hormone deficiency (7), chronic inflammation (8), nutritional deficiencies, gut microbiome, endothelial dysfunction (9) and irradiation $(6,10,11,12)$. Several studies have demonstrated that total body irradiation (TBI), given as a conditioning regimen before hematopoietic stem-cell transplantation, represents a major risk factor for developing MS and CVD $(10,11,12,13,14,15)$.

In the LEA cohort, MS was found in $18.9 \%$ of young adults (mean age 21 years) who had received TBI during childhood (6). Interestingly, even among survivors with MS, patients who received TBI for AL are leaner than those who did not (16). We have recently shown in a cohort of 1025 leukemia survivors that irradiated patients had a particular profile of MS with significantly more pronounced insulin resistance parameters (higher triglycerides, higher plasma glucose levels and lower HDL-C levels) despite lower BMIs and lower waist circumferences when compared to controls (15).

MS is the clinico-biological expression of an insulinresistant state. Over the years, accumulating evidence has revealed that insulin resistance is the consequence of a deficit in the capacity of subcutaneous fat to store excess energy, resulting in increased accumulation of fat in undesired sites, a phenomenon that has been described as ectopic fat deposition (17). The role of this 'limited subcutaneous AT expandability' is consistent with the severe insulin-resistant state found in patients with lipodystrophic conditions (18). Given the high prevalence of MS, and despite a lower body weight among survivors who received TBI, we hypothesized that exposure to radiation leads to abnormal fat storage with ectopic fat deposition development deposition and insulin resistance. Previous work by Cousin et al. reported that irradiation alters the proliferation and differentiation capacity of adipocyte precursor cells in mice (19). However, the effects of radiation exposure on human AT are unknown. No study to date had the opportunity to explore the AT functionality on AT biopsy in these young leukemia survivors.

To assess the impact of $\mathrm{TBI}$ on AT, we compared the morphological and functional characteristics of AT between childhood AL survivors with MS and who had received, or had not received TBI treatment.

\section{Materials and methods}

\section{Patients}

All the patients described here were included in the LEA program, a historical multicenter and prospective cohort established in 2003 to evaluate the long-term health condition, quality of life and socioeconomic status of survivors of childhood leukemia $(3,20)$. During the LEA follow-up, medical check-ups were repeated biannually until the age of 20 years and every 4 years thereafter. Since 2007, MS, defined, according to the NCEP-ATPIII criteria (4), was systematically searched for in all adults. For this study, the clinical data and treatments related to AL were obtained by reviewing each patient's medical records. The following inclusion criteria were used: patients were (i) included in the LEA cohort, (ii) aged $>18$ years, (iii) in follow-up care in the French 'PACA-Corse' area, (iv) diagnosed with MS during the LEA follow-up and (v) had provided written informed consent for participation in this study. All patients were included between May and September 2015. The French National Program for Clinical Research and the French National Cancer Institute approved the LEA program. This study obtained ANSM agreement on February 20th, 2015 and approval from CPP SUD MEDITERRANEE V on April 8th, 2015 (201S-A00170-49). The National Clinical Trial number is 02696304.

\section{Clinical and biological parameters}

The following anthropometric data were collected: body weight, height, BMI, waist- and hip circumference (measured by the same physician). The habitus, personal or family history of CVD were equally collected. Dietary intake was evaluated by a dietician using Bilnut 7.5 Windows software. Physical activity was assessed by the specific 
questionnaire: 'Global Physical Activity Questionnaire' (21). Indirect calorimetry (Quark PFT ergo, COSMED, Italy) was done to estimate the resting metabolic rate.

Patients underwent blood analysis after overnight fasting that included a lipid profile, fasting plasma glucose, liver-enzyme levels, plasma adipokines and apolipoproteins. Total plasma apoC-III and apoC-II levels were determined using an immuno-turbidimetric assay (Kamiya Biomedical Company, Seattle, WA, USA). A specific ELISA was used to measure serum levels of adiponectin (Quantikine Human Adiponectin, R\&D Systems) and leptin (Active Human Leptin DSL Systems). The insulin resistance homeostasis model (HOMA-IR) was calculated as: fasting plasma glucose $(\mathrm{mmol} / \mathrm{L}) \times$ fasting plasma insulin $(\mathrm{mIU} / \mathrm{L}) / 22.5$.

\section{Body composition and AT distribution}

\section{Dual X-ray absorptiometry (DEXA)}

Body composition was assessed using the gold-standard dual-energy X-ray absorptiometry (Lunar iDXA, GE Healthcare).

\section{Magnetic resonance imaging}

Abdominal MRI (DIXON technique, 3T-MRI, Siemens VERIO, slices acquisition centered at L4-L5) was conducted to analyze the distribution of abdominal AT, that is, superficial subcutaneous abdominal AT (sSAT), deep subcutaneous abdominal AT (dSAT), or visceral abdominal AT (VAT), with high replicability (22) (Supplementary material A, see section on supplementary data given at the end of this article). MRI was conducted at the Center for Magnetic Resonance in Biology and Medicine (CEMEREM).

\section{Liver fat content assessment}

Proton magnetic resonance spectroscopy ( ${ }^{1} \mathrm{H}$-MRS) was used to quantify ectopic fat deposition in the liver $(23,24)$. Patients were scanned in a head first supine position, using 3T MRI-scanner (Siemens VERIO). A single-voxel proton spectroscopy sequence (PRESS; repetition time $=1000$ $\mathrm{ms}$, echo time $=35 \mathrm{~ms}$, number of excitations $=16$, and bandwidth of $2000 \mathrm{~Hz}$ ) was used to determine the molecular content of lipids and water. A spectroscopic voxel was positioned in three different orientations (axial, coronal and sagittal). Minimal rectangular voxel dimensions were $20 \times 15 \times 15 \mathrm{~mm}^{3}$. All acquisitions were performed during breath holding. Due to the heterogeneity of the ectopic fat content in liver, the hepatic triglyceride content was assessed in three different locations (left and right liver lobes and the hepatic dome) (25). Two single scan spectra (calculation of water saturation) and two 16-scan spectra were acquired. We observed in each tissue the water spectrum resonance at $4.7 \mathrm{ppm}$ and the lipid resonance $\left(\mathrm{CH}_{2}\right.$ of triglycerides (TG)) at $1.3 \mathrm{ppm}$. Spectra analyses were performed using AMARES (MRUI package) under an Interactive Data Language environment. The liver TG content was expressed as a relative percentage of water signal (\% TG = amplitude of TG peak in 16 scans spectrum/ amplitude of water peak in single scan spectrum $\times 100$ ). Using results of the three different areas in liver, we calculated the mean hepatic TG content.

\section{Abdominal subcutaneous AT biopsy}

A needle aspiration of abdominal sSAT was performed under local anesthesia. AT samples (200-1000 mg) were obtained and washed in physiological saline. A portion of each biopsy was placed immediately in liquid nitrogen and stored at $-80^{\circ} \mathrm{C}$ until analysis. Another portion was placed in phosphate-buffered saline (PBS) for flow cytometry and cell culture.

\section{Sample preparation and real-time PCR}

Total RNA was extracted by needle aspiration from sSAT or from culture using the RNAeasy Lipid Mini kit (Qiagen), according to the manufacturer's recommendations. RNA concentration and quality was confirmed using nanodrop (Nd-100, Nanodrop Technologies). cDNA was synthesized from 500 ng of total RNA. Real-time quantitative PCR assays were performed with Sybr green mixes using a thermocycler stratagem Mx3005. We used 18S rRNA as a normalization control. Gene expression changes were evaluated using the LIVAK method (26). Primer designs can be provided on request. For the differentiation markers in culture, real-time PCR assays were run on a StepOne detection system (Life Technologies/Applied Biosystem), and relative gene expression was calculated using the delta-cycle threshold method and normalized to PUM expression.

\section{Flow cytometry}

Samples of sSAT were stored in PBS at room temperature and sent to the STROMALab institute in Toulouse on the same day. Stroma-vascular fraction and mature adipocytes were separated as previously described (27). Stroma-vascular fraction cells were incubated with PBS 
supplemented with FcR Block reagent (MiltenyiBiotec). Staining was performed by incubating cells for $30 \mathrm{~min}$ at $4^{\circ} \mathrm{C}$ with conjugated primary antibodies or an appropriate immunoglobulin $\mathrm{G}$ isotype control (BD Biosciences). DAPI was used for the viability control. Cells were analyzed on a FACS Canto II flow cytometer (BD Biosciences). Data acquisition was performed with FACS Diva software and analysis was performed with Kaluza software (Beckman-Coulter). Pre-adipocyte cells were characterized as $\mathrm{CD}^{2} 4^{+} / \mathrm{CD}^{-} 5^{-} / \mathrm{CD}^{-} 1^{-}$.

\section{Pre-adipocyte culture}

The stroma-vascular fraction was isolated from human SSAT obtained from 14 samples, as previously described $(27,28)$. Briefly, the stroma-vascular fraction was formed by plating overnight in DMEM medium supplemented with 10\% newborn calf serum, $250 \mu \mathrm{g} / \mathrm{mL}$ amphotericin, $5 \mu \mathrm{g} / \mathrm{mL}$ streptomycin and $5 \mathrm{U} / \mathrm{mL}$ penicillin. After $24 \mathrm{~h}$, the cultures were washed extensively using PBS to remove residual nonadherent cells. Cells were incubated at $37^{\circ} \mathrm{C}$ under $5 \%$ $\mathrm{CO}_{2}$, and the medium was changed twice weekly. Cultures were pursued until cells reached $75 \%$ confluence. Adipose differentiation was then induced by adding dexamethasone $(1 \mu \mathrm{M})$, indomethacin $(60 \mu \mathrm{M})$, isobutyl-methyl xanthine (IBMX, $450 \mu \mathrm{M})$, insulin $(5 \mu \mathrm{g} / \mathrm{mL})$ and rosiglitazone $(2 \mu \mathrm{M})$ for 3 days. The medium was then replaced with the same supplementation medium without IBMX for four additional days. Adipogenic differentiation was evaluated by quantification of the expression of differentiation markers. Adipocytes were quantified by counting the number of lipid-loaded cells under the microscope (Nikon, TE2000S) in randomized sections of the culture plates.

\section{Statistical analysis}

All statistical analyses were performed using Prism software (GraphPad software 6.0). Values are expressed as mean \pm standard deviation (s.D.). The Gaussian distribution of all parameters was tested and parametric (unpaired Student's $t$-test) or nonparametric tests (Mann-Whitney test) were selected, as appropriate. Fisher's exact test was used for non-continuous variables. Statistical significance was defined as $P<0.05$.

\section{Results}

\section{Patients characteristics}

Among the 409 adult patients included in the LEA cohort and followed in the French area 'PACA-Corse', 337 patients were screened for MS. Of these 337 patients, 37 had been diagnosed with MS during the LEA follow-up and fulfilled all the inclusion criteria, of which 24 agreed to participate in the study (flow chart in Supplementary Table A). Twelve patients who had received TBI as a conditioning regimen before hematopoietic stem-cell transplantation for AL were included in the 'TBI group'. The 12 other patients who received chemotherapy alone (i.e. without TBI) were included in the 'no-TBI group'. Patients characteristics at the time of leukemia are summarized in Table 1 and more details on leukemia treatment are available in Supplementary Table B.

For all 24 patients, the diagnosis of MS was made during the LEA follow-up. The mean age at MS diagnosis was $29.0 \pm 8.4$ years in the TBI group vs $27.3 \pm 6.5$ years in the no-TBI group (NS). From MS diagnosis until inclusion in the present study, some patients changed their lifestyle and dietary habits. At the time of inclusion, nine patients still fulfilled three or more criteria for MS (4/12 in the no-TBI group and 5/12 in the TBI group).

Patients characteristics at inclusion, according to TBI treatment, are summarized in Table 2 . The gender ratio (M/F) was respectively 1.4 in the no-TBI group and 0.5 in the TBI group. Mean age of patients at inclusion was 31.1 years in the no-TBI group and 32.9 years in the TBI group (NS). One male in the TBI group experienced a coronary event at the age of 30 years. Blood pressure was not different between groups.

Apolipoprotein CII and NEFA levels were increased in the TBI group compared to the no-TBI group (respectively $54 \mathrm{vs} 33 \mathrm{mg} / \mathrm{L}, P=0.05$ and 0.6 vs $0.4 \mathrm{mmol} / \mathrm{L}, P=0.05$ ). Triglycerides and Apolipoprotein CIII levels tended to be higher in the TBI group without reaching statistical significance. At inclusion, there was no difference in the glucose parameters between the TBI and the no-TBI groups. Five patients were diagnosed with type- 2 diabetes (three from the TBI group and two from the no-TBI group).

The hormonal status of each patient was evaluated at inclusion. Six patients from the TBI group and one from the no-TBI group had a history of hypothyroidism, which was corrected with thyroid hormone. No patient had a growth-hormone deficiency. Three patients in the TBI group presented with hypogonadism at inclusion (two men, one woman). Hormonal data according to group and gender are reported in Supplementary Table C.

\section{Irradiated women are leaner with less intra-abdominal fat compared to no-TBI group}

Among patients who developed MS, those who received TBI were significantly smaller and thinner than the

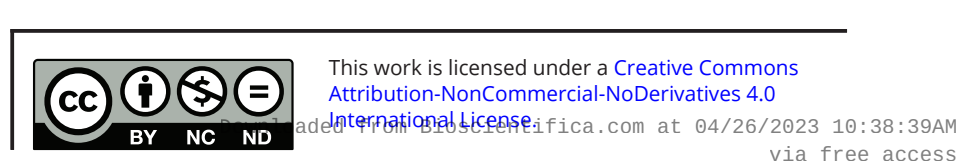


Table 1 Patients medical history.

\begin{tabular}{l}
\hline Characteristics of leukemia history \\
Age at AL diagnosis (years, mean \pm s.D.) \\
Leukemia type, $n$ \\
ALL \\
AML \\
BMI at $A L$ diagnosis ( $Z$-score, mean \pm S.D.) \\
BMI at $A L$ diagnosis $\left(\mathrm{kg} / \mathrm{m}^{2}\right.$, mean \pm S.D.) \\
Time from AL diagnosis to last LEA visit (years, mean \pm S.D.) \\
\hline
\end{tabular}

\begin{tabular}{c}
\hline No-TBI $(n=12)$ \\
\hline $9.9 \pm 4.3$ \\
7 \\
5 \\
$0.7 \pm 3.3$ \\
$19 \pm 8$ \\
$18.4 \pm 8.7$ \\
\hline
\end{tabular}

\begin{tabular}{|c|c|}
\hline TBI $(n=12)$ & $\boldsymbol{P}$ \\
\hline $6.8 \pm 4.5$ & 0.1 \\
\hline 10 & 0.37 \\
\hline 2 & \\
\hline $0.5 \pm 1.0$ & 0.31 \\
\hline $17 \pm 2$ & 0.62 \\
\hline $23.8 \pm 6.8$ & 0.1 \\
\hline
\end{tabular}

AL, acute leukemia; ALL, acute lymphoblastic leukemia; AML, acute myeloid leukemia; BMI, body mass index (weight/height²); TBI, total body irradiation

no-TBI group $(15,16)$ (Table 3$)$. Mean BMI decreased by five points in the TBI group ( $25 \mathrm{vs} 30 \mathrm{~kg} / \mathrm{m}^{2}, P=0.06$ ). This difference was more pronounced in women, known to develop more AT than men (mean BMI in TBI women at $26 \mathrm{vs} 34 \mathrm{~kg} / \mathrm{m}^{2}$ in no-TBI women, $P=0.03$ ). After irradiation, waist and hip circumferences were $\sim 10 \mathrm{~cm}$ and $20 \mathrm{~cm}$ lower in men (NS) and women $(P=0.02)$, respectively. Gynoid and android fat masses, evaluated by DEXA were significantly decreased in women from the TBI group vs no-TBI (respectively, $P=0.02$ and $P=0.045$ ) (Table 3). Consistent with these data, there was a significant decrease in plasma-leptin levels in women from the TBI group ( $32 \mathrm{vs} 53 \mathrm{ng} / \mathrm{mL}, P=0.045$ ) (Table 3 ). Adiponectin concentrations were decreased in irradiated men (1.0 vs $2.5 \mu \mathrm{g} / \mathrm{mL}, P=0.04)$.

In order to distinguish peripheral and intra-abdominal AT accumulation in MS patients, we performed abdominal
MRIs in the two groups. Twenty-two patients could have an MRI, but one patient presented with a contraindication and another refused the MRI. Intra-abdominal AT was significantly decreased in women within the TBI group (228 vs $373 \mathrm{~cm}^{2}, P=0.02$ ) (Table 4). Other measures of AT (total AT surface as well as other specific AT sub-compartments: superficial compartmentalization: SSAT, that is, peripheral and deep intra-abdominal AT (dSAT and VAT) (29)) tended to decrease in both genders within the TBI group but without reaching the statistical significance.

Nutritional assessment and physical activity of the patients are described in Supplementary Table D. No difference was found between the two groups except for a decrease in resting energy expenditure in the TBI group in agreement with the thinner phenotype.

Table 2 Patients characteristics at inclusion in the present study $(n=24)$.

\begin{tabular}{l}
\hline \\
\hline Demographic characteristics \\
Age (years, mean \pm S.D.) \\
Gender ratio (M/F) \\
Cardiovascular characteristics \\
Smoking, $n$ \\
Diabetes, $n$ \\
Cardiovascular disease, $n$ \\
Systolic blood pressure $(\mathrm{mmHg}$, mean \pm S.D.) \\
Diastolic blood pressure $(\mathrm{mmHg}$, mean \pm S.D.) \\
Lipid parameters \\
Triglycerides (mmol/L, mean \pm S.D.) \\
Apolipoprotein CII (mg/L, mean \pm S.D.) \\
Apolipoprotein CIII (mg/L, mean \pm S.D.) \\
NEFA (mmol/L, mean \pm S.D.) \\
HDL-C (mmol/L, mean \pm S.D.) \\
Glucose parameters \\
Fasting glucose (mmol/L, mean \pm S.D.) \\
Fasting insulin (mIU/L, mean \pm S.D.) \\
HOMA-IR (mean \pm S.D.)
\end{tabular}

\begin{tabular}{c}
\hline No-TBI $(n=12)$ \\
$31.1 \pm 7.1$ \\
1.4 \\
6 \\
2 \\
0 \\
$120 \pm 11$ \\
$70 \pm 12$ \\
$1.5 \pm 0.7$ \\
$33 \pm 15$ \\
$105 \pm 39$ \\
$0.4 \pm 0.2$ \\
$1.1 \pm 0.2$ \\
$5.4 \pm 0.9$ \\
$22 \pm 15$ \\
$5.6 \pm 4.6$
\end{tabular}

\begin{tabular}{ccc}
\hline TBI $(n=12)$ & & $\mathbf{P}$ \\
\cline { 1 - 1 } $32.9 \pm 8.2$ & & 0.57 \\
0.5 & & 0.41 \\
& & 0.07 \\
3 & & 1 \\
1 & & 1 \\
$117 \pm 10$ & & 0.43 \\
$70 \pm 10$ & & 0.97 \\
& & \\
$2.1 \pm 0.9$ & & 0.18 \\
$54 \pm 27$ & & $\mathbf{0 . 0 5}$ \\
$130 \pm 40$ & & 0.10 \\
$0.6 \pm 0.2$ & & $\mathbf{0 . 0 5}$ \\
$1.0 \pm 0.3$ & & 0.63 \\
$5.5 \pm 1.3$ & \\
$25 \pm 13$ & 0.95 \\
$6.4 \pm 3.8$ & 0.55 \\
& 0.68 \\
\hline
\end{tabular}

AL, acute leukemia; ALL, acute lymphoblastic leukemia; AML, acute myeloid leukemia; BMI, body mass index (weight/height²); HDL-C, high-density lipoprotein cholesterol; HOMA-IR, homeostatic model assessment of insulin resistance ((glucose $\times$ insulin)/22.5); NEFA, non-esterified fatty acid; TBI, total body irradiation. Bold indicates statistical significance.

https://ec.bioscientifica.com https://doi.org/10.1530/EC-18-0497 (c) 2019 The authors Published by Bioscientifica Ltd

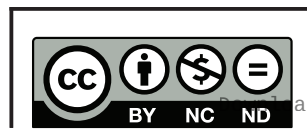

This work is licensed under a Creative Commons Attribution-NonCommercial-NoDerivatives 4.0 delnternationab bicense.ifica com at 04/26/2023 10:38:39AM 
Table 3 Anthropometric data and body composition of patients.

\begin{tabular}{|c|c|c|c|c|c|c|c|c|c|}
\hline & \multicolumn{3}{|c|}{ Women } & \multicolumn{3}{|c|}{ Men } & \multicolumn{3}{|c|}{ All patients } \\
\hline & No-TBI $(n=5)$ & $\mathrm{TBI}(n=8)$ & $P$ & No-TBI $(n=7)$ & $\mathrm{TBI}(n=4)$ & $P$ & No-TBI $(n=12)$ & $\mathrm{TBI}(n=12)$ & $P$ \\
\hline $\begin{array}{l}\text { Weight (kg, } \\
\text { mean } \pm \text { S.D.) }\end{array}$ & $86 \pm 25$ & $63 \pm 20$ & 0.04 & $84 \pm 21$ & $68 \pm 17$ & 0.53 & $85 \pm 22$ & $65 \pm 19$ & 0.02 \\
\hline $\begin{array}{l}\text { Height (cm, } \\
\text { mean } \pm \text { s.D.) }\end{array}$ & $159 \pm 7$ & $156 \pm 6$ & 0.51 & $175 \pm 5$ & $167 \pm 12$ & 0.30 & $168 \pm 10$ & $159 \pm 10$ & 0.03 \\
\hline $\begin{array}{c}\mathrm{BMI}\left(\mathrm{kg} / \mathrm{m}^{2}\right. \\
\text { mean } \pm \text { S.D. })\end{array}$ & $34 \pm 7$ & $26 \pm 7$ & 0.03 & $28 \pm 8$ & $24 \pm 3$ & 0.32 & $30 \pm 8$ & $25 \pm 6$ & 0.06 \\
\hline $\begin{array}{l}\text { Waist } \\
\text { circumference } \\
\text { (cm, mean } \pm \text { S.D.) }\end{array}$ & $112 \pm 14$ & $90 \pm 14$ & 0.02 & $98 \pm 20$ & $90 \pm 11$ & 0.65 & $104 \pm 18$ & $90 \pm 13$ & 0.04 \\
\hline $\begin{array}{l}\text { Hip circumference } \\
(\mathrm{cm}, \text { mean } \pm \text { S.D. })\end{array}$ & $113 \pm 19$ & $92 \pm 13$ & 0.02 & $97 \pm 16$ & $87 \pm 10$ & 0.44 & $104 \pm 18$ & $90 \pm 12$ & 0.03 \\
\hline $\begin{array}{l}\text { Total fat mass (\%, } \\
\text { mean } \pm \text { S.D.) }\end{array}$ & $49 \pm 5$ & $41 \pm 7$ & 0.065 & $32 \pm 10$ & $33 \pm 9$ & 0.78 & $39 \pm 12$ & $38 \pm 8$ & 0.84 \\
\hline $\begin{array}{l}\text { Lean mass (\%, } \\
\text { mean } \pm \text { s.D.) }\end{array}$ & $48 \pm 5$ & $56 \pm 6$ & 0.045 & $64 \pm 9$ & $64 \pm 8$ & 0.72 & $58 \pm 11$ & $58 \pm 8$ & 0.87 \\
\hline $\begin{array}{r}\text { Gynoid fat mass } \\
(\%, \text { mean } \pm \text { S.D. })\end{array}$ & $54 \pm 7$ & $42 \pm 7$ & 0.02 & $32 \pm 12$ & $34 \pm 11$ & 0.92 & $41 \pm 15$ & $39 \pm 9$ & 0.71 \\
\hline $\begin{array}{l}\text { Android fat mass } \\
(\%, \text { mean } \pm \text { s.D. })\end{array}$ & $57 \pm 4$ & $48 \pm 8$ & 0.045 & $42 \pm 14$ & $41 \pm 8$ & 0.92 & $48 \pm 13$ & $45 \pm 8$ & 0.53 \\
\hline $\begin{array}{l}\text { Fat mass/height } \\
\text { (mean } \pm \text { S.D.) }\end{array}$ & $31 \pm 3$ & $26 \pm 3$ & 0.045 & $19 \pm 6$ & $20 \pm 4$ & 0.53 & $24 \pm 8$ & $24 \pm 5$ & 0.86 \\
\hline $\begin{array}{l}\text { Adiponectin ( } \mu \mathrm{g} / \\
\mathrm{mL}, \text { mean } \pm \text { S.D.) }\end{array}$ & $4.2 \pm 2.6$ & $2.8 \pm 1.9$ & 0.30 & $2.5 \pm 1.7$ & $1.0 \pm 0.2$ & 0.04 & $3.2 \pm 2.2$ & $2.2 \pm 1.7$ & 0.13 \\
\hline $\begin{array}{l}\text { Leptin }(\mathrm{ng} / \mathrm{mL} \text {, } \\
\text { mean } \pm \text { s.D. })\end{array}$ & $53 \pm 10$ & $32 \pm 15$ & 0.045 & $16 \pm 16$ & $12 \pm 11$ & 0.48 & $31 \pm 23$ & $25 \pm 17$ & 0.51 \\
\hline
\end{tabular}

BMI, body mass index (weight/height²); TBI, total body irradiation. Bold indicates statistical significance.

\section{Liver steatosis increased in the group of irradiated patients}

Since we have previously shown that irradiated patients have an increased insulin resistance despite lower body weight (15), we then studied liver steatosis, a characteristic feature of insulin resistance state and lipodystrophic syndromes. The mean liver fat content in the TBI group was almost two times greater (17 vs 9\%, $P=0.008$ ) (Fig. 1).
When we studied independently women and men, hepatic triglyceride content was increased in both sex in the TBI group, but the difference did not reach statistical significance: respectively 17 vs $8 \%(P=0.06)$ in women and 16 vs $10 \%(P=0.17)$ in men. Accordingly, gamma GT enzymes were increased in the TBI compared to the no-TBI group (59 vs $40 \mathrm{IU} / \mathrm{mL}, P=0.045$ ). Liver transaminases levels were unchanged between TBI and no-TBI groups (respectively 39 vs $28 \mathrm{IU} / \mathrm{L}, \quad P=0.18$ for AST,

Table 4 Abdominal fat distribution using MRI.

\begin{tabular}{|c|c|c|c|c|c|c|c|c|c|}
\hline & \multicolumn{3}{|c|}{ Women } & \multicolumn{3}{|c|}{ Men } & \multicolumn{3}{|c|}{ All patients } \\
\hline & No-TBI $(n=5)$ & $\mathrm{TBI}(n=7)$ & $P$ & No-TBI $(n=6)$ & $\mathrm{TBI}(n=4)$ & $P$ & No-TBI $(n=11)$ & $\mathrm{TBI}(n=11)$ & $P$ \\
\hline $\begin{array}{l}\text { TAT }\left(\mathrm{cm}^{2},\right. \\
\text { mean } \pm \text { s.D. })\end{array}$ & $638 \pm 191$ & $424 \pm 203$ & 0.07 & $338 \pm 114$ & $318 \pm 134$ & 0.61 & $474 \pm 214$ & $385 \pm 181$ & 0.21 \\
\hline $\begin{array}{l}\text { VAT }\left(\mathrm{cm}^{2}\right. \\
\text { mean } \pm \text { S.D. })\end{array}$ & $119 \pm 36$ & $87 \pm 23$ & 0.11 & $115 \pm 40$ & $105 \pm 50$ & 0.76 & $117 \pm 36$ & $94 \pm 34$ & 0.14 \\
\hline $\begin{array}{l}\text { Intra-abdominal AT } \\
\left(\mathrm{cm}^{2}, \text { mean } \pm \text { s.D. }\right)\end{array}$ & $373 \pm 114$ & $228 \pm 108$ & 0.02 & $232 \pm 73$ & $207 \pm 74$ & 0.47 & $296 \pm 115$ & $221 \pm 93$ & 0.06 \\
\hline $\begin{array}{l}\text { SAT }\left(\mathrm{cm}^{2}\right. \\
\text { mean } \pm \text { S.D. })\end{array}$ & $519 \pm 167$ & $336 \pm 204$ & 0.11 & $223 \pm 79$ & $213 \pm 86$ & 0.76 & $358 \pm 195$ & $291 \pm 177$ & 0.47 \\
\hline $\begin{array}{l}\text { dSAT }\left(\mathrm{cm}^{2}\right. \\
\text { mean } \pm \text { S.D. })\end{array}$ & $254 \pm 86$ & $141 \pm 111$ & 0.07 & $118 \pm 38$ & $102 \pm 25$ & 0.91 & $179 \pm 93$ & $127 \pm 89$ & 0.12 \\
\hline $\begin{array}{l}\text { SSAT }\left(\mathrm{cm}^{2}\right. \\
\text { mean } \pm \text { S.D. })\end{array}$ & $265 \pm 94$ & $196 \pm 96$ & 0.15 & $106 \pm 42$ & $111 \pm 62$ & 0.76 & $178 \pm 107$ & $165 \pm 92$ & 0.79 \\
\hline
\end{tabular}

AT, adipose tissue; intra-abdominal AT = dSAT+VAT; dSAT, deep SAT; SAT, subcutaneous adipose tissue; SSAT, superficial SAT; TAT, total AT; TBI, total body irradiation; VAT, visceral AT. Bold indicates statistical significance.

https://ec.bioscientifica.com https://doi.org/10.1530/EC-18-0497 (c) 2019 The authors Published by Bioscientifica Ltd

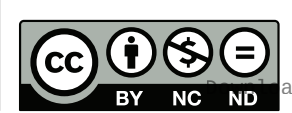

This work is licensed under a Creative Commons Attribution-NonCommercial-NoDerivatives 4.0 enternationab ticense ifica . com at 04/26/2023 10:38:39Am 


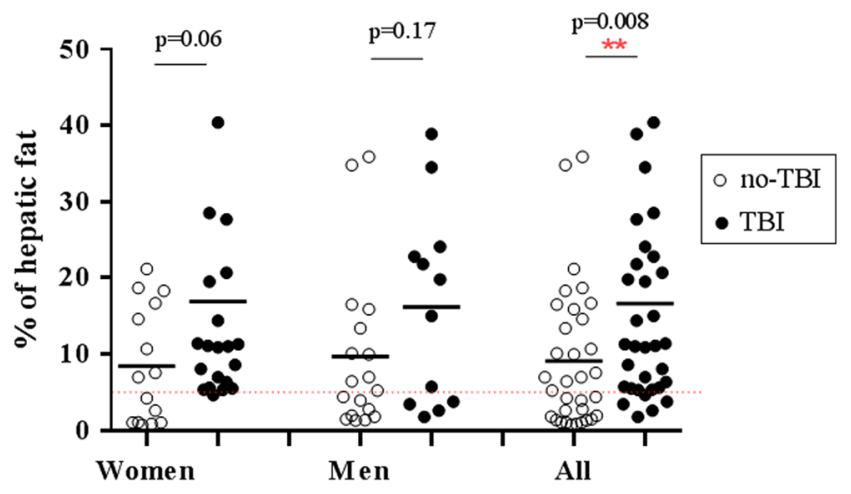

Figure 1

Liver fat content. Hepatic triglyceride content was measured by proton magnetic resonance spectroscopy $\left({ }^{1} \mathrm{H}-\mathrm{MRS}\right)$ using three voxels for each patient (left, right liver lobes and hepatic dome) for women, men and all patients in no-TBI group (white circles) and TBI group (black circles). ${ }^{*} P P<0.01$

and 46 vs $33 \mathrm{IU} / \mathrm{L}, P=0.19$ for ALT). Two patients had regular alcohol consumption (respectively 6 and $8 \mathrm{~g} /$ day) and one patient had festive consumption in the no-TBI group; none in the TBI group reported drinking. The more pronounced liver steatosis was observed in the TBI group despite lower intra-abdominal fat. This discordance was illustrated by the ratio of the mean liver fat content related to intra-abdominal AT that was more than two times higher after TBI (0.08 vs $0.03, P=0.02)$.

\section{Defect in fat storage and adipocyte differentiation in SAT of irradiated patients}

We performed needle aspiration of sSCAT in 22 patients in order to analyze the gene expression of several proteins involved in AT homeostasis and for the study of pre-adipocyte differentiation in culture. Analysis of gene expression in sSAT revealed a decreased expression of genes involved in uptake and fatty acid biosynthesis, and in insulin sensitivity, in the TBI group: that is, $39 \%$ decrease for SREBP-1C gene expression $(P=0.01)$ and $36 \%$ decrease for CIDEA gene expression $(P=0.004)$. Adiponectin and $P P A R-\gamma$ gene expression tended to decrease $(18 \%$ decrease for adiponectin $(P=0.08)$ and $18 \%$ decrease for PPAR- $\gamma(P=0.11))$. In addition, mRNA level of collagen $1 \mathrm{a} 1$ was $36 \%$ lower in the TBI group $(P=0.03)$. No significant difference was found for the AT inflammatory parameters (Fig. 2).

Pre-adipocytes number in sSAT evaluated by flow cytometry and expressed in cell number/g of AT did not differ between the two groups of patients (Fig. 3A). The adipogenic differentiation was then assessed by counting mature adipocytes and performing RT-qPCR on cell culture after 7 days of differentiation. As shown in Fig. 3B and $\mathrm{C}$, the number of mature adipocytes tended to decrease in the TBI group $\left(261 \pm 197\right.$ vs $173 \pm 89$ adipocytes $/ \mathrm{mm}^{3}$ in no-TBI and TBI groups respectively, NS). As expected, adipocyte differentiation induced increased expression of PPAR- $\gamma, a P 2$, leptin, $L P L$ and GPDH in both groups. However, the induced expression of most of these genes was 2-4 times lower in differentiated cells belonging to the TBI group compared to no-TBI ( $P=0.04$ for all), indicating that the extent of adipocyte differentiation was reduced following TBI (Fig. 3D).

\section{Discussion}

To our knowledge, this is the first study which evaluates the impact of irradiation on AT in survivors of childhood AL. We have shown that patients who received TBI during childhood and who developed MS in adulthood have nearly two times more liver fat than AL survivors who developed MS but did not received irradiation. These differences were observed although irradiated patients had less body fat. This lower AT mass development is supported at the molecular level by lower gene expression of proteins involved in fatty acid metabolism and fat storage associated to a profound alteration of pre-adipocyte differentiation.

Thus, we first have confirmed that patients who underwent irradiation were more prone to metabolic abnormalities despite the lower BMI and lower waist circumference (16). However, waist circumference, which is correlated with visceral AT in the general population, is one of the five criteria used to define MS in the classical NCEP-ATP-III definition (4). Thus, in this specific population of irradiated patients, the measurement of waist circumference is not accurate when defining MS. These data highlight the need for clinicians to search for metabolic disorders in all patients who had TBI during childhood, even when the patient's BMI and waist circumference are within normal range.

Liver fat is strongly correlated with insulin resistance, type-2 diabetes and CVD (30). An important result of this study is the nearly two-fold increase in liver fat found in the TBI group. Other studies have also reported an increase in liver steatosis in survivors of pediatric cancers after irradiation $(12,31,32)$. Epidemiological studies have consistently demonstrated a strong association between VAT and hepatic triglyceride content (30). However, we found a higher rate of liver steatosis after TBI, despite lower abdominal AT (significantly decreased

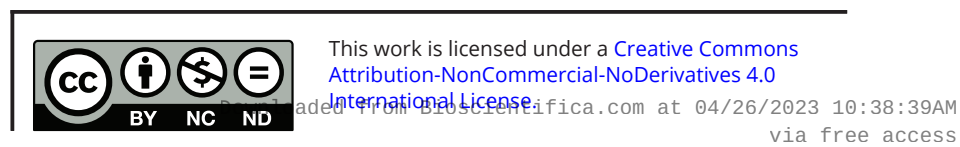


INFLAMMATION

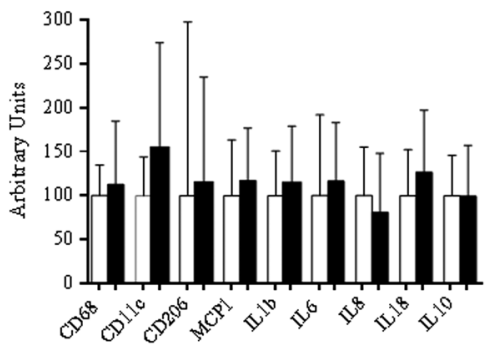

FIBROSIS

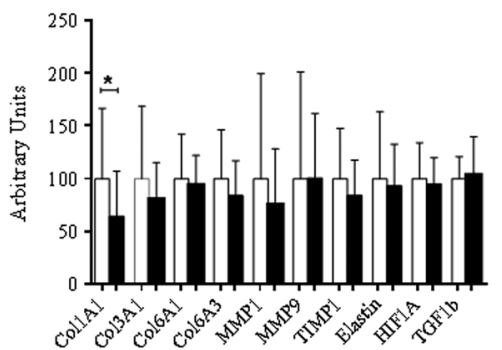

LIPOGENESIS

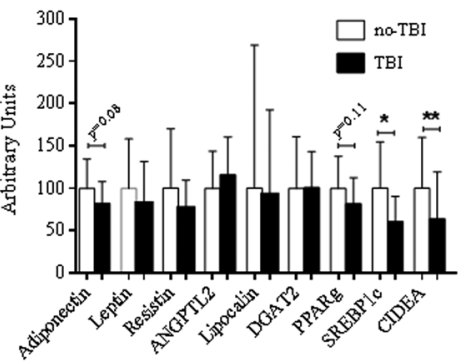

Figure 2

Impact of TBI on total subcutaneous adipose tissue. Gene expression levels involved in inflammation, fibrosis and lipogenesis between the no-TBI group (white bars) $(n=10)$ and the TBI group (black bars) $(n=10)$. ANGPTL2, angiopoietin like 2; CD, cluster of differentiation; CIDEA, cell death-inducing DNA fragmentation factor alpha-like effector A; COL, collagen; DGAT2, diacylglycerol O-acyltransferase 2; HIF, hypoxia inducible factor; IL, interleukin; MCP1, monocyte chemoattractant protein-1; MMP, matrix metallopeptidase; PPAR, peroxisome proliferator-activated receptor; SREBP1c, sterol regulatory element-binding protein 1; TBI, total body irradiation; TIMP, tissue inhibitor of metalloproteinases; TGF, transforming growth factor.

in women). In accordance with our results, a recent study on nonhuman primates showed a significant reduction in VAT associated with a higher rate of liver steatosis after radiation exposure (33). We hypothesize that irradiation could alter the capacity of visceral adipocytes to undergo hyperplasia and/or differentiation, thus explaining this particular feature of high liver fat despite low VAT. Numerous recent studies have demonstrated that ectopic fat deposits are secondary to the relative inability of SAT to properly store energy and expand when there is a positive energy balance (34). In lipodystrophic syndromes, impairment in the ability of SAT to properly
A

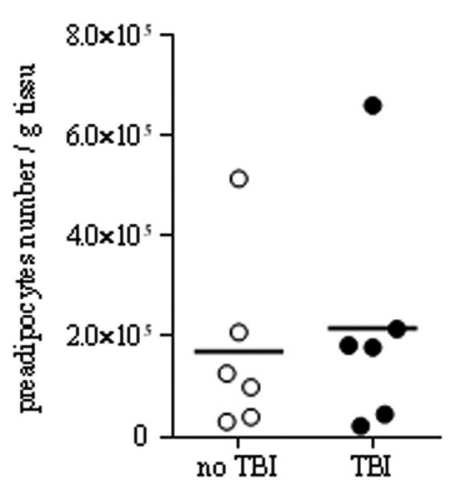

$\mathrm{D}$
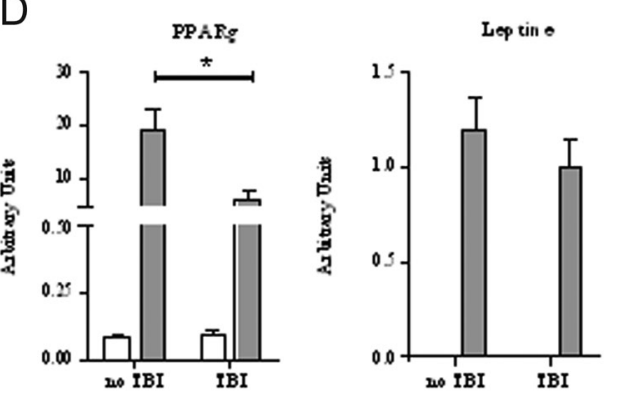

$\mathrm{B}$
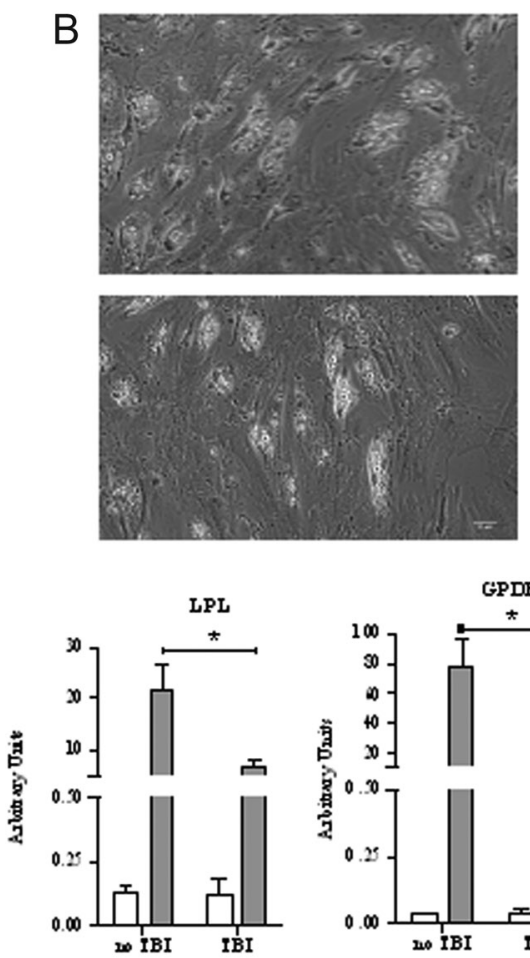

C

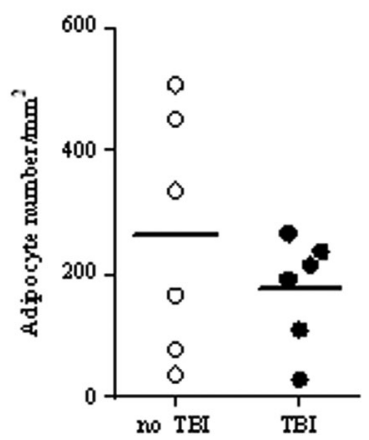

Figure 3

Differentiation of pre-adipocytes in culture. (A) Flow cytometry was performed to compare the number of pre-adipocyte cells/g of total SAT in the stromal-vascular fraction from the no-TBI group (black circles) $(n=6)$ and the TBI group (black squares) $(n=6)$. (B) Picture of pre-adipocytes culture after 7 days of differentiation in no-TBI group (up) and TBI group (down). (C) Comparison of the number of adipocytes/mm $\mathrm{m}^{3}$ after 7 days of differentiation.

(D) Expression levels of genes involved in adipocyte differentiation in patients who received TBI $(n=8)$ or not $(n=7)$. Cultured pre-adipocytes were studied before (D0) (white bars) and at 7 days (D7) (gray bars) of differentiation. ${ }^{*} P<0.05$. aP2, adipocyte protein 2; GPDH, glycerol-3-phosphate dehydrogenase; LPL, lipoprotein lipase; PPAR, peroxisome proliferator-activated receptor.

https://ec.bioscientifica.com https://doi.org/10.1530/EC-18-0497 (c) 2019 The authors Published by Bioscientifica Ltd
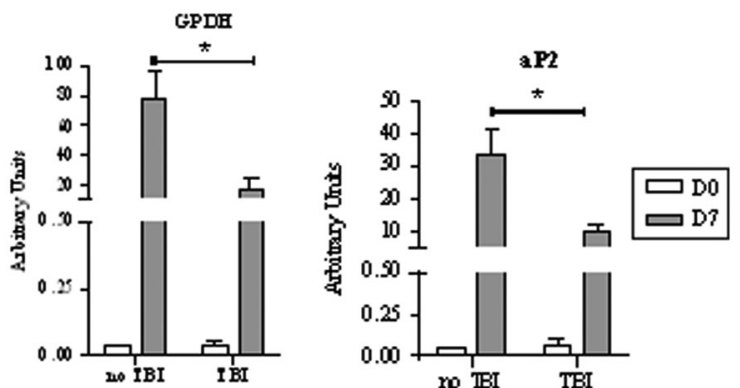
expand leads to ectopic fat accumulation with insulin resistance and to fatty liver (18). Accordingly, in a recent 4-year longitudinal study, the authors demonstrated that large areas of SAT at baseline seemed to be protective against NAFLD (nonalcoholic fatty liver disease) (35). Similarly, we observed a significantly higher rate of liver steatosis associated with a lower BMI, and a trend toward decreased TAT and SAT after TBI in patients who had been irradiated. All these observations are in favor of an inability of AT to properly expand after irradiation. It is important to note that one patient in the TBI group was diagnosed with hepatic fibrosis during the follow-up period, as a consequence of liver steatosis (diagnosed with a fibroscan). We demonstrate here that the screening for metabolic disorders and NAFLD in patients who received TBI in childhood is essential for their long time follow-up.

When we studied the functional aspects of SAT in the long-term AL survivors after irradiation, we found a significantly reduced gene expression of CIDEA and SREBP1C, which are involved in the uptake and biosynthesis of fatty acids and play an important role in metabolic homeostasis. Indeed CIDEA level in white AT is positively correlated with expandability of SAT, insulin sensitivity and healthy obesity in mice (36). SREBP1c is an important pro-adipogenic transcription factor that directly regulates the expression of several key genes in lipid metabolism and also regulates adipogenesis (37). The reduced gene expression of CIDEA and SREBP1c in SAT observed after irradiation could explain the incapacity of SAT to properly expand, leading to ectopic fat accumulation. Moreover, our results show that the differentiation capacity of adipocyte precursor cells was altered in the SAT of irradiated patients, with a clear reduction in the expression levels of several key genes involved in preadipocyte differentiation and lipid accumulation. This lower extent of adipose differentiation following TBI was consistent with a slightly reduced adipocyte number in culture in the TBI group compared to the no-TBI one. These results were also consistent with the significant decrease in the proliferation and differentiation capacity of pre-adipocytes following irradiation in mice (19). It would have been informative to measure adipocyte size in these patients. Unfortunately, the AT samples we obtained by needle aspiration were too disrupted to allow a proper histological analysis. This minimally invasive technique was used instead of the biopsy for ethical reasons because patients have usually already undergone many invasive treatments.

We did not find any difference between groups regarding local inflammation in SAT. This is in agreement with the fact that liver steatosis and insulin resistance are not related to AT inflammation in lipodystrophic syndromes (38). Altogether, these results support the direct effect of irradiation on AT, leading to alteration in pre-adipocyte differentiation and AT fat storage, thus causing increased TG accumulation within the liver.

Our data on irradiated patients were particularly clear for women known to develop more AT than men. Indeed, the differences in BMI and waist circumference between the two groups were more pronounced for women and a decrease in fat mass and intra-abdominal fat was only observed in women. Other studies have also reported that girls are more prone to having a lower BMI after irradiation $(32,39)$. Further studies are needed to explore the reasons for a higher susceptibility to irradiation in women.

Several other factors are involved in the greater risk of developing MS and CVD, specifically after irradiation. TBI is associated with a high risk of developing endocrine disorders at the time of treatment and later on: i.e., growth-hormone deficiency, hypothyroidism and gonadic dysfunction (39). In the present study, no growth-hormone deficiency, which is frequently associated with insulin resistance, was diagnosed at inclusion. Despite being within the normal range, thyroid levels did statistically differ between the two groups; however, this difference is unlikely to have caused insulin resistance. Three patients in the TBI group presented with hypogonadism at inclusion. Hypogonadism could lead to insulin resistance but few data show a link between low levels of testosterone and liver steatosis (40). Regarding other risk factors for MS, our previous study (41) did not find any correlation between the use of steroid for $\mathrm{AL}$ treatment and MS in irradiated patients. An increased BMI at the time of $\mathrm{AL}$ diagnosis has been proposed as a risk factor for developing MS in TBI patients (6), but we did not find any difference in the BMIs of the two groups (at the time of $\mathrm{AL}$ ).

\section{Conclusion}

In conclusion, long-term survivors of childhood $\mathrm{AL}$ who received TBI treatment may present features of lipodystrophy, even decades later. Thus, long-term appropriate follow-up is necessary for these patients. NAFLD should be detected in all patients after TBI. Clinicians should continue to provide screening and preventive care for MS and CVD to irradiated patients, even though they have a normal waist circumference and BMI. 


\section{Supplementary data}

This is linked to the online version of the paper at https://doi.org/10.1530/ EC-18-0497.

\section{Declaration of interest}

The authors declare that there is no conflict of interest that could be perceived as prejudicing the impartiality of the research reported.

\section{Funding}

This study was supported by an AORC (Appel d'Offre de Recherche Clinique) from the Assistance Publique of Marseille, France. S Visentin was supported by Aix-Marseille University (Année Recherche). The authors thank Anaïs Giry for technical assistance. The LEA cohort is funded by the French National Clinical Research Program, the French National Cancer Institute (InCA), the 'Laurette Fugain' association, the French National Research Agency (ANR), the 'Ligue contre le cancer' association, the Cancéropôle PACA, the Regional Council PACA and the French Institute for Public Health Research (IRESP)

\section{Author contribution statement}

S B, G M, C O and M C A contributed to the study's concept and design. $G M$ and $S V$ contributed to the recruitment of patients. S V, S B and $\mathrm{M} \mathrm{N}$ contributed to the experimental part (data collection, AT biopsies, MRI, RTq PCR, etc.). S V, M B, M G, I A and B G contributed to the MRI and ${ }^{1} \mathrm{H}$-spectroscopy and their interpretation. B C contributed to the cytometry and pre-adipocyte experiments. S V and S B contributed to the analysis and interpretation of the data, the statistical analysis and drafting of the manuscript. P A contributed to the statistical analyses. M G, B C, B G, M M, $\mathrm{RV}, \mathrm{MB}, \mathrm{HC}$ and $\mathrm{MC}$ A contributed to the critical revision of the manuscript. G M and S B are the guarantors of this work and, as such, had full access to all the data used in the study and take responsibility for the integrity of the data and the accuracy of the data analyses.

\section{References}

1 Pui CH, Carroll WL, Meshinchi S \& Arceci RJ. Biology, risk stratification, and therapy of pediatric acute leukemias: an update. Journal of Clinical Oncology 201129 551-565. (https://doi. org/10.1200/JCO.2010.30.7405)

2 Pui CH, Cheng C, Leung W, Rai SN, Rivera GK, Sandlund JT, Ribeiro RC, Relling MV, Kun LE, Evans WE, et al. Extended follow-up of long-term survivors of childhood acute lymphoblastic leukemia New England Journal of Medicine 2003349 640-649. (https://doi. org/10.1056/NEJMoa035091)

3 Michel G, Bordigoni P, Simeoni MC, Curtillet C, Hoxha S, Robitail S, Thuret I, Pall-Kondolff S, Chambost H, Orbicini D, et al. Health status and quality of life in long-term survivors of childhood leukaemia: the impact of haematopoietic stem cell transplantation. Bone Marrow Transplantation 200740 897-904. (https://doi.org/10.1038/ sj.bmt.1705821)

4 Grundy SM, Cleeman JI, Daniels SR, Donato KA, Eckel RH, Franklin BA, Gordon DJ, Krauss RM, Savage PJ, Smith SC, et al. Diagnosis and management of the metabolic syndrome an American Heart Association/National Heart, Lung, and Blood Institute scientific statement. Circulation 2005112 2735-2752. (https://doi. org/10.1161/CIRCULATIONAHA.105.169404)

5 Nottage KA, Ness KK, Li C, Srivastava D, Robison LL \& Hudson MM. Metabolic syndrome and cardiovascular risk among long-term survivors of acute lymphoblastic leukaemia - from the
St. Jude Lifetime Cohort. British Journal of Haematology 2014165 364-374. (https://doi.org/10.1111/bjh.12754)

6 Oudin C, Simeoni MC, Sirvent N, Contet A, Begu-Le Coroller A, Bordigoni P, Curtillet C, Poirée M, Thuret I, Play B, et al. Prevalence and risk factors of the metabolic syndrome in adult survivors of childhood leukemia. Blood 2011117 4442-4448. (https://doi. org/10.1182/blood-2010-09-304899)

7 Taskinen M, Lipsanen-Nyman M, Tiitinen A, Hovi L \& SaarinenPihkala UM. Insufficient growth hormone secretion is associated with metabolic syndrome after allogeneic stem cell transplantation in childhood. Journal of Pediatric Hematology/Oncology 200729 529-534. (https://doi.org/10.1097/MPH.0b013e3180f61b67)

8 Turcotte LM, Yingst A \& Verneris MR. Metabolic syndrome after hematopoietic cell transplantation: at the intersection of treatment toxicity and immune dysfunction. Biology of Blood and Marrow Transplantation 201622 1159-1166. (https://doi.org/10.1016/j. bbmt.2016.03.016)

9 Takatsuka H, Wakae T, Mori A, Okada M, Okamoto T \& Kakishita E. Effects of total body irradiation on the vascular endothelium. Clinical Transplantation 200216 374-377. (https://doi.org/10.1034/j.13990012.2002.02035.x)

10 Bizzarri C, Pinto RM, Ciccone S, Brescia LP, Locatelli F \& Cappa M. Early and progressive insulin resistance in young, non-obese cancer survivors treated with hematopoietic stem cell transplantation. Pediatric Blood and Cancer 201562 1650-1655. (https://doi. org/10.1002/pbc.25603)

11 Mayson SE, Parker VER, Schutta MH, Semple RK \& Rickels MR. Severe insulin resistance and hypertriglyceridemia after childhood total body irradiation. Endocrine Practice 201319 51-58. (https://doi. org/10.4158/EP12115.OR)

12 Adachi M, Asakura Y, Muroya K, Goto H \& Kigasawa H. Abnormal adipose tissue distribution with unfavorable metabolic profile in five children following hematopoietic stem cell transplantation: a new etiology for acquired partial lipodystrophy. Clinical Pediatric Endocrinology 201322 53-64. (https://doi.org/10.1292/cpe.22.53)

13 Chemaitilly W, Boulad F, Oeffinger KC \& Sklar CA. Disorders of glucose homeostasis in young adults treated with total body irradiation during childhood: a pilot study. Bone Marrow Transplantation 200944 339-343. (https://doi.org/10.1038/bmt.2009.40)

14 Chow EJ, Simmons JH, Roth CL, Baker KS, Hoffmeister PA, Sanders JE $\&$ Friedman DL. Increased cardiometabolic traits in pediatric survivors of acute lymphoblastic leukemia treated with total body irradiation. Biology of Blood and Marrow Transplantation 201016 1674-1681. (https://doi.org/10.1016/j.bbmt.2010.05.016)

15 Oudin C, Berbis J, Bertrand Y, Vercasson C, Thomas F, Chastagner P, Ducassou S, Kanold J, Tabone MD, Paillard C, et al. Prevalence and characteristics of metabolic syndrome in adults from the French childhood leukemia survivors' cohort: a comparison with controls from the French population. Haematologica 2018103 645-654. (https://doi.org/10.3324/haematol.2017.176123)

16 Wei C, Thyagiarajan MS, Hunt LP, Shield JPH, Stevens MCG \& Crowne EC. Reduced insulin sensitivity in childhood survivors of haematopoietic stem cell transplantation is associated with lipodystropic and sarcopenic phenotypes. Pediatric Blood and Cancer 201562 1992-1999. (https://doi.org/10.1002/pbc.25601)

17 Lotta LA, Gulati P, Day FR, Payne F, Ongen H, van de Bunt M, Gaulton KJ, Eicher JD, Sharp SJ, Luan J, et al. Integrative genomic analysis implicates limited peripheral adipose storage capacity in the pathogenesis of human insulin resistance. Nature Genetics 201749 17-26. (https://doi.org/10.1038/ng.3714)

18 Fiorenza CG, Chou SH \& Mantzoros CS. Lipodystrophy: pathophysiology and advances in treatment. Nature Reviews Endocrinology 20117 137-150. (https://doi.org/10.1038/ nrendo.2010.199)

19 Poglio S, Galvani S, Bour S, André M, Prunet-Marcassus B, Pénicaud L, Casteilla L \& Cousin B. Adipose tissue sensitivity to 
radiation exposure. American Journal of Pathology 2009 174 44-53. (https://doi.org/10.2353/ajpath.2009.080505)

20 Berbis J, Michel G, Chastagner P, Sirvent N, Demeocq F, Plantaz D, Barlogis V, Contet A, Poirée M, Kanold J, et al. A French cohort of childhood leukemia survivors: impact of hematopoietic stem cell transplantation on health status and quality of life. Biology of Blood and Marrow Transplantation 201319 1065-1072. (https://doi. org/10.1016/j.bbmt.2013.04.015)

21 Bull FC, Maslin TS \& Armstrong T. Global physical activity questionnaire (GPAQ): nine country reliability and validity study. Journal of Physical Activity and Health 20096 790-804. (https://doi. org/10.1123/jpah.6.6.790)

22 Cornier MA, Després JP, Davis N, Grossniklaus DA, Klein S, Lamarche B, Lopez-Jimenez F, Rao G, St-Onge MP, Towfighi A, et al. Assessing adiposity: a scientific statement from the American Heart Association. Circulation 2011124 1996-2019. (https://doi. org/10.1161/CIR.0b013e318233bc6a)

23 Dutour A, Abdesselam I, Ancel P, Kober F, Mrad G, Darmon P, Ronsin O, Pradel V, Lesavre N, Martin JC, et al. Exenatide decreases liver fat content and epicardial adipose tissue in patients with obesity and type 2 diabetes: a prospective randomized clinical trial using magnetic resonance imaging and spectroscopy. Diabetes, Obesity and Metabolism 201618 882-891. (https://doi. org/10.1111/dom.12680)

24 Gaborit B, Abdesselam I, Kober F, Jacquier A, Ronsin O, Emungania O, Lesavre N, Alessi MC, Martin JC, Bernard M, et al. Ectopic fat storage in the pancreas using $1 \mathrm{H}-\mathrm{MRS}$ : importance of diabetic status and modulation with bariatric surgery-induced weight loss. International Journal of Obesity 201539 480-487. (https://doi. org/10.1038/ijo.2014.126)

25 Choi Y, Lee JM, Yi NJ, Kim H, Park MS, Hong G, Yoo T, Suh SW, Lee HW, Lee KW, et al. Heterogeneous living donor hepatic fat distribution on MRI chemical shift imaging. Annals of Surgical Treatment and Research 201589 37-42. (https://doi.org/10.4174/ astr.2015.89.1.37)

26 Livak KJ \& Schmittgen TD. Analysis of relative gene expression data using real-time quantitative PCR and the 2(-Delta Delta C(T)) method. Methods 200125 402-408. (https://doi.org/10.1006/ meth.2001.1262

27 Planat-Benard V, Silvestre JS, Cousin B, André M, Nibbelink M, Tamarat R, Clergue M, Manneville C, Saillan-Barreau C, Duriez M, et al. Plasticity of human adipose lineage cells toward endothelial cells: physiological and therapeutic perspectives. Circulation 2004109 656-663. (https://doi.org/10.1161/01. CIR.0000114522.38265.61)

28 Puissant B, Barreau C, Bourin P, Clavel C, Corre J, Bousquet C, Taureau C, Cousin B, Abbal M, Laharrague P, et al. Immunomodulatory effect of human adipose tissue-derived adult stem cells: comparison with bone marrow mesenchymal stem cells. British Journal of Haematology 2005129 118-129. (https://doi. org/10.1111/j.1365-2141.2005.05409.x)

29 Kelley DE, Thaete FL, Troost F, Huwe T \& Goodpaster BH. Subdivisions of subcutaneous abdominal adipose tissue and insulin resistance. American Journal of Physiology: Endocrinology and Metabolism 2000278 E941-E948. (https://doi.org/10.1152/ ajpendo.2000.278.5.E941)

30 Kotronen A, Westerbacka J, Bergholm R, Pietiläinen KH \& YkiJärvinen $\mathrm{H}$. Liver fat in the metabolic syndrome. Journal of Clinical Endocrinology and Metabolism 200792 3490-3497. (https://doi. org/10.1210/jc.2007-0482)

31 Rajendran R, Abu E, Fadl A \& Byrne CD. Late effects of childhood cancer treatment: severe hypertriglyceridaemia, central obesity, non alcoholic fatty liver disease and diabetes as complications of childhood total body irradiation. Diabetic Medicine $2013 \mathbf{3 0}$ e239-e242. (https://doi.org/10.1111/dme.12234)

32 Tomita Y, Ishiguro H, Yasuda Y, Hyodo H, Koike T, Shimizu T, Morimoto T, Hattori $\mathrm{K}$, Matsumoto $\mathrm{M}$, Inoue $\mathrm{H}$, et al. High incidence of fatty liver and insulin resistance in long-term adult survivors of childhood SCT. Bone Marrow Transplantation 201146 416-425. (https://doi.org/10.1038/bmt.2010.144)

33 Kavanagh K, Dendinger MD, Davis AT, Register TC, DeBo R, Dugan G \& Cline JM. Type 2 diabetes is a delayed late effect of whole-body irradiation in nonhuman primates. Radiation Research 2015183 398-406. (https://doi.org/10.1667/RR13916.1)

34 Karpe F \& Pinnick KE. Biology of upper-body and lower-body adipose tissue - link to whole-body phenotypes. Nature Reviews Endocrinology 201511 90-100. (https://doi.org/10.1038/nrendo.2014.185)

35 Kim D, Chung GE, Kwak MS, Seo HB, Kang JH, Kim W, Kim YJ, Yoon JH, Lee HS \& Kim CY. Body fat distribution and risk of incident and regressed nonalcoholic fatty liver disease. Clinical Gastroenterology and Hepatology 201614 132.e4-138.e4. (https://doi. org/10.1016/j.cgh.2015.07.024)

36 Abreu-Vieira G, Fischer AW, Mattsson C, de Jong JMA, Shabalina IG, Rydén M, Laurencikiene J, Arner P, Cannon B, Nedergaard J, et al. Cidea improves the metabolic profile through expansion of adipose tissue. Nature Communication 20156 7433. (https://doi.org/10.1038/ ncomms8433)

37 Payne VA, Au WS, Lowe CE, Rahman SM, Friedman JE, O'Rahilly S $\&$ Rochford JJ. C/EBP transcription factors regulate SREBP1c gene expression during adipogenesis. Biochemical Journal 2009425 215-223. (https://doi.org/10.1042/BJ20091112)

38 Vegiopoulos A, Rohm M \& Herzig S. Adipose tissue: between the extremes. EMBO Journal 201736 1999-2017. (https://doi. org/10.15252/embj.201696206)

39 Rose SR, Horne VE, Howell J, Lawson SA, Rutter MM, Trotman GE $\&$ Corathers SD. Late endocrine effects of childhood cancer. Nature Reviews Endocrinology 201612 319-336. (https://doi.org/10.1038/ nrendo.2016.45)

40 Mody A, White D, Kanwal F \& Garcia JM. Relevance of low testosterone to non-alcoholic fatty liver disease. Cardiovascular Endocrinology 20154 83-89. (https://doi.org/10.1097/ XCE.0000000000000057)

41 Oudin C, Auquier P, Bertrand Y, Contet A, Kanold J, Sirvent N, Thouvenin S, Tabone MD, Lutz P, Ducassou S, et al. Metabolic syndrome in adults who received hematopoietic stem cell transplantation for acute childhood leukemia: an LEA study. Bone Marrow Transplantation 201550 1438-1444. (https://doi.org/10.1038/ bmt.2015.167)

Received in final form 3 March 2019

Accepted 7 March 2019

Accepted Preprint published online 7 March 2019 https://ec.bioscientifica.com https://doi.org/10.1530/EC-18-0497
(C) 2019 The authors Published by Bioscientifica Ltd
This work is licensed under a Creative Commons Attribution-NonCommercial-NoDerivatives 4.0 elnternationad ticense ifica . com at 04/26/2023 10:38:39AM 